\title{
Doxapram Treatment for Apnea of Prematurity: A Systematic Review
}

\author{
Roseanne J.S. Vliegenthart Christine H. ten Hove Wes Onland \\ Anton H.L.C. van Kaam \\ Department of Neonatology, Emma Childrens' Hospital AMC, Amsterdam, The Netherlands
}

\section{Key Words}

Apnea of prematurity · Doxapram · Efficacy · Safety

\begin{abstract}
Background: Apnea of prematurity (AOP) is a common complication of preterm birth, for which caffeine is the first treatment of choice. In case of persistent AOP, doxapram has been advocated as an additional therapy. Objective: To identify and appraise all existing evidence regarding efficacy and safety of doxapram use for AOP in infants born before 34 weeks of gestational age. Methods: All studies reporting on doxapram use for AOP were identified by searching electronic databases, references from relevant studies, and abstracts from the Societies for Pediatric Research. Two reviewers independently assessed study eligibility and quality, and extracted data on study design, patient characteristics, efficacy and safety outcomes. Results: The randomized controlled trials showed less apnea during doxapram treatment when compared to placebo, but no difference in treatment effect when compared to theophylline. No serious adverse effects were reported. We identified 28 observational studies consisting mainly of cohort studies and case series $(\mathrm{n}=$ 1,994). There was considerable heterogeneity in study design and quality. Most studies reported a positive effect of doxapram on apnea rate. A few studies reported on longterm outcomes with conflicting results. A range of possible doxapram-related short-term adverse effects were reported,
\end{abstract}

\section{KARGER}

E-Mail karger@karger.com www.karger.com/neo

\section{The Author(s) \\ Published by S. Karger AG, Basel \\ Karger \\ Open access}

This article is licensed under the Creative Commons Attribution NonCommercial-NoDerivatives 4.0 International License (CC BY NC-ND) (http://www.karger.com/Services/OpenAccessLicense). Usage and distribution for commercial purposes as well as any distribution of modified material requires written permission. sometimes associated with the use of higher doses. Conclusion: Based on the limited number of studies and level of evidence, no firm conclusions on the efficacy and safety of doxapram in preterm infants can be drawn. For this reason, routine use cannot be recommended. A large multicenter randomized controlled trial is urgently needed to provide more conclusive evidence.

(C) 2016 The Author(s)

Published by S. Karger AG, Basel

\section{Background}

\section{Description of the Condition}

Apnea of prematurity (AOP) is a common complication of preterm birth and can be classified as central, obstructive or mixed $[1,2]$. Central AOP is characterized by no or insufficient respiratory drive due to immaturity of the breathing center in the brainstem. During obstructive AOP the infant does display breathing efforts, but no air enters the lungs due to obstruction of the (upper) airways. Mixed AOP is most common in preterm infants and is characterized by a combination of central and obstructive apnea. AOP is often accompanied by oxygen desaturations and/or bradycardia. The number of apneas in (very) preterm infants progressively increases over the first 4-5 weeks of life and then tends to decrease in the following weeks [3]. AOP has been associated with impaired neurodevelopmental outcome and retinopathy of 
prematurity $[3,4]$. Furthermore, treating apnea with invasive mechanical ventilation may lead to secondary lung injury, thereby increasing the risk of developing bronchopulmonary dysplasia (BPD).

\section{Description of the Intervention}

Caffeine is the treatment of choice for AOP, as it is associated with improved neurodevelopment [5-7]. Doxapram has been advocated as an additional treatment if AOP persists during caffeine treatment. The modes of action of doxapram are multiple, such as stimulating the breathing center in the brain [8] and stimulating peripheral chemoreceptors in the carotid body [9]. To date, only a small number of randomized controlled trials (RCTs), summarized in a Cochrane review [8], have assessed its efficacy and safety. There is, however, also a considerable amount of nonrandomized evidence on the use of doxapram, which has not been reviewed so far. Such a review seems relevant because, despite the limited randomized evidence, doxapram is widely used in some parts of the world [10].

\section{Objective}

The objective of this review is to identify and appraise all existing evidence regarding the efficacy and safety of doxapram use for AOP.

\section{Methods}

\section{Criteria for Considering Studies for this Review}

RCTs, cohort studies, case-control studies, case series and case reports were eligible for this review if they reported on doxapram use for AOP in preterm infants born before 34 weeks of gestation and reported at least one of the prespecified outcome measures. The search strategy was limited to articles written in English, German, French or Dutch.

\section{Types of Outcome Measures}

The following outcome measures on efficacy and safety of doxapram were collected: number of apneas, carbon dioxide partial pressure $\left(\mathrm{pCO}_{2}\right)$, need for mechanical ventilation, extubation failure, BPD, heart rate and electrocardiography abnormalities, systolic blood pressure, feeding intolerance, gastrointestinal bleeding, necrotizing enterocolitis (NEC), cerebral blood flow, intracranial hemorrhage, jitteriness, seizures, central nervous system stimulation as measured by amplitude-integrated electroencephalography, neurodevelopmental outcome, including neurological examination, cerebral palsy and the Bayley Scales of Infant Development (BSID), and mortality.

A Systematic Review on Doxapram

\section{Search Methods for Identification of Studies}

An electronic search for relevant articles was performed independently by two authors (R.J.S.V., C.H.t.H.) using Medline, Embase and the Cochrane Library. The only restriction was that studies had to be performed on humans. In addition, the two authors also performed a hand search for eligible studies in the reference lists of published trials and review articles, and the abstracts of the Pediatric Academic Societies and the European Society for Paediatric Research (from 1990 onwards).

\section{Selection of Studies}

Based on the abstract, two authors (R.J.S.V. and C.H.t.H.) classified the eligible studies into three groups: 'clearly relevant', 'clearly not relevant' and 'possibly relevant'. A full-text review was done on all, except those classified as 'clearly not relevant'. Any disagreement was resolved by consensus.

\section{Data Extraction}

Two authors (R.J.S.V. and W.O.) independently extracted, if applicable, all prespecified outcome measures and the following additional study data: year of publication, region of origin, number of hospitals including patients for the study, type of study and data collection (e.g. retrospective or prospective), period of data collection, eligibility criteria, patient characteristics [such as birth weight, gestational age (GA), gender], number of patients included, treatment with antenatal corticosteroids and postnatal surfactant, and doxapram regimens (postnatal age at start, loading dose, minimum and maximum dose allowed, duration of therapy, cumulative dose, and route of administration).

\section{Assessment of Risk of Bias}

Quality assessment of the included RCTs was done by appraising the method of randomization, blinding of intervention, blinding of outcome and completeness to follow-up. The level of bias was based on the criteria reported in the Cochrane Handbook for Systematic Reviews of Interventions [11]. Funnel plots were made to assess possible publication bias. The STROBE statement was used for the quality assessment of cohort and case-control studies [12]. For case series, quality assessment was based on a clear description of the study objective, the inclusion period, inclusion and exclusion criteria, the intervention, the outcome measures, and completeness of follow-up.

\section{Analyses of Treatment Effects}

Data on similar study outcomes reported in the RCTs with regard to efficacy or safety of doxapram were pooled if available, using Review Manager (RevMan) version 5.3 (Copenhagen: Nordic Cochrane Centre, Cochrane Collaboration, 2012). Treatment effect estimates were expressed as typical relative risk for dichotomous outcomes, and weighted mean difference for continuous data with a $95 \%$ confidence interval. By design, the cohort studies and case series could not be pooled. The results of the case-control studies were too heterogeneous to be pooled in a meta-analysis. Therefore, the results of the cohort and case-control studies were summarized in a descriptive and narrative manner.

\section{Assessment of Heterogeneity}

Heterogeneity between trials was assessed by inspecting the forest plots and using the $\mathrm{I}^{2}$ statistic to quantify the impact of heterogeneity. The degree of heterogeneity was classified as defined by the Cochrane Neonatal Review Group: $<25 \%=$ no heterogene- 
Fig. 1. Flowchart for study retrieval.

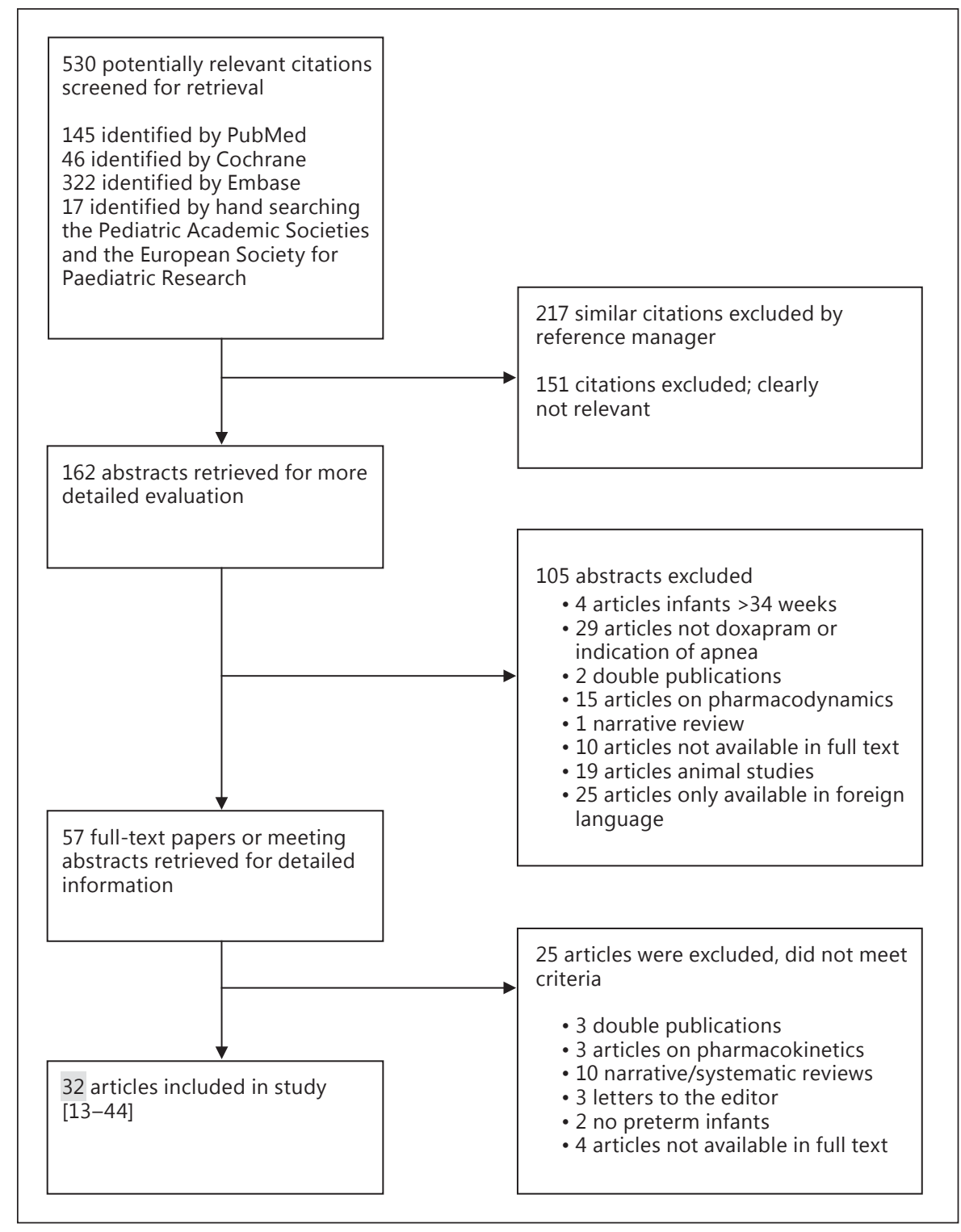

ity; $25-49 \%=$ low heterogeneity; $50-74 \%=$ moderate heterogeneity; $\geq 75 \%$ = high heterogeneity.

Possible causes of statistical heterogeneity were explored using prespecified subgroup analysis. Subgroups were defined as: GA $<28$ weeks, doxapram dose $<1.5 \mathrm{mg} \cdot \mathrm{kg}^{-1} \cdot \mathrm{h}^{-1}$ versus doxapram dose $\geq 1.5 \mathrm{mg} \cdot \mathrm{kg}^{-1} \cdot \mathrm{h}^{-1}$.

\section{Results}

\section{Study Characteristics}

A total of 530 articles were identified in the different databases using the search strategy mentioned above (fig. 1). Of these, 368 were excluded because they were duplicate or 'clearly not relevant' citations. In addition, 130 studies were excluded for the reasons mentioned in figure 1 . This left 32 studies for the final analyses, 4 RCTs [13-16], 1 prospective crossover study [17], 2 case-control studies $[18,19]$, and 25 cohort, case series or case reports studies [20-44]. Four studies were only available in abstract form $[19,23,24,38]$.

The study characteristics are summarized in table 1 . All studies vary greatly regarding the year of publication (1984-2014), number of included infants and doxapram dose $\left(0.2\right.$ to $\left.2.5 \mathrm{mg} \cdot \mathrm{kg}^{-1} \cdot \mathrm{h}^{-1}\right)$. Most studies included patients with a GA around 30 weeks, whereas only 8 studies included infants with a mean GA of less than 27 weeks. 
Table 1. Study characteristics

\begin{tabular}{|c|c|c|c|c|c|c|c|c|c|c|c|c|c|c|c|}
\hline First author & Year & $\mathrm{N} / \mathrm{n}$ & Mean GA, weeks & Mean BW, g & Dose & Caffeine & Apnea & HT & CNS & Seizures & IVH $>2$ & GI & NEC & $\mathrm{BPD}$ & LFU \\
\hline \multicolumn{16}{|l|}{$R C T$} \\
\hline Barrington [13] & 1998 & $27 / 29$ & $25.8 / 25.6$ & $931 / 933$ & 1.0 & $\mathrm{~N}$ & NR & $2 / 1$ & $1 / 0$ & NR & NR & NR & $1 / 1$ & NR & NR \\
\hline Eyal [14] & 1985 & $9 / 7$ & 30.1 & 1,289 & 2.5 & $\mathrm{~N}$ & $\downarrow$ & NR & NR & NR & NR & NR & NR & NR & NR \\
\hline Eyal [14] & 1985 & $6 / 4$ & 27.5 & 808 & 2.5 & $\mathrm{~N}$ & $\downarrow$ & NR & NR & NR & NR & NR & NR & NR & NR \\
\hline Möller [15] & 1999 & $14 / 20$ & $30.57 / 29.8$ & $1,316 / 1,218$ & 0.5 & $\mathrm{Y}$ & $\downarrow$ & NR & ND & NR & NR & NR & NR & NR & NR \\
\hline Peliowski [16] & 1989 & $11 / 10$ & $30.7 / 31.3$ & $1,303 / 1,598$ & 1.5 & $\mathrm{~N}$ & $\downarrow$ & NR & NR & NR & NR & NR & NR & NR & NR \\
\hline \multicolumn{16}{|l|}{ Cohort study } \\
\hline Czaba-Hnizdo [20] & 2014 & $13 / 61$ & 25.5 & 755 & $0.5-1$ & NR & NR & NR & NR & $\uparrow \mathrm{EEG}$ act. & NR & NR & NR & NR & NR \\
\hline Fischer [21] & 2013 & $54 / 51$ & $28.2 / 29.5$ & $1,089 / 1,362$ & $0.5-1.5$ & $\mathrm{Y}$ & NR & NR & NR & $\mathrm{NR}$ & NR & NR & NR & NR & NR \\
\hline Prins [22] & 2014 & 122 & $<32.0$ & NR & NR & NR & NR & NR & NR & NR & ND & NR & ND & NR & NR \\
\hline Roignot [23] & 2014 & $53 / 51$ & $27.9 / 27.8$ & $1,116 / 1,049$ & NR & $\mathrm{Y}$ & NR & NR & NR & NR & ND & NR & NR & ND & ND \\
\hline Ten Hove [24] & 2014 & $65 / 130$ & $\mathrm{NR}$ & NR & NR & NR & NR & NR & NR & NR & $\uparrow$ & NR & NR & $\uparrow$ & $\downarrow$ \\
\hline Kumita [25] & 1991 & $11 / 20$ & $28.5 / 29.0$ & $1,090 / 1,182$ & $0.2-2.5$ & NR & $\downarrow$ & ND & NR & NR & NR & $\mathrm{Y}$ & Y & NR & NR \\
\hline Yamazaki [26] & 2001 & $106 / 198$ & $28.1 / 29.6$ & $1,088 / 1,087$ & $0.2-1.0$ & $\mathrm{~N}$ & $\downarrow$ & NR & NR & NR & ND & NR & $0 / 0$ & NR & NR \\
\hline \multicolumn{16}{|l|}{ Case-control study } \\
\hline Sreenan [18] & 2001 & $40 / 40$ & $26.4 / 26.5$ & $824 / 843$ & $0.5-2.5$ & $\mathrm{~N}$ & NR & NR & NR & $5 / 4$ & $7 / 7$ & NR & $4 / 4$ & NR & NR \\
\hline Zayek [19] & 2008 & $227 / 411$ & $24.8 / 26.2$ & $715 / 879$ & NR & NR & NR & NR & NR & NR & NR & NR & NR & NR & ND \\
\hline \multicolumn{16}{|l|}{ Crossover study } \\
\hline Eyal [17] & 1985 & $5 / 7$ & 30 & 1,215 & 2.5 & $\mathrm{~N}$ & NR & NR & NR & NR & NR & NR & NR & NR & NR \\
\hline \multicolumn{16}{|l|}{ Case series } \\
\hline Alpan [27] & 1984 & 11 & 29.9 & 1,120 & 2.5 & $\mathrm{~N}$ & $\downarrow$ & NR & $9 \%$ & NR & NR & NR & NR & NR & $9 \%$ \\
\hline Bairam [28] & 1992 & 8 & 29.0 & 1,444 & $0.25-1.00$ & $\mathrm{~N}$ & $\downarrow$ & $0 \%$ & $0 \%$ & $0 \%$ & NR & NR & NR & NR & NR \\
\hline Bairam [29] & 1986 & 8 & 30.5 & 1,407 & 0.25 & $?$ & $\downarrow$ & NR & NR & NR & NR & NR & NR & NR & NR \\
\hline Barrington [30] & 1986 & 12 & 28.5 & 1,015 & $2-2.5$ & $\mathrm{~N}$ & $\downarrow$ & $Y>1.5$ & $17 \%$ & $17 \%$ & NR & NR & NR & NR & NR \\
\hline Barrington [31] & 1987 & 18 & 26.6 & 886 & $0.5-2.5$ & $\mathrm{Y}$ & $\downarrow$ & $Y>1.5$ & NR & $0 \%$ & NR & NR & NR & NR & NR \\
\hline Beaudry [32] & 1988 & 13 & 29.4 & 1,247 & $2-2.5$ & $\mathrm{Y}$ & NR & $Y>1.5$ & $100 \%$ & $0 \%$ & $8 \%$ & $23 \%$ & $23 \%$ & $23 \%$ & $8 \%$ \\
\hline Dani [33] & 2005 & 20 & 28.6 & 1,095 & $0.5-2.5$ & $\mathrm{~N}$ & NR & $0 \%$ & NR & NR & $0 \%$ & NR & NR & NR & NR \\
\hline Hayakawa [34] & 1986 & 12 & 28.9 & 1,211 & $0.5-2.5$ & $\mathrm{~N}$ & $\downarrow$ & NR & $17 \%$ & NR & NR & $17 \%$ & NR & NR & NR \\
\hline Lando [35] & 2005 & 88 & 26.6 & 858 & $\mathrm{NR}$ & NR & NR & NR & NR & NR & NR & NR & $14 \%$ & NR & R-PDQ $\downarrow$ \\
\hline Maillard [36] & 2001 & 40 & 28.9 & 1,220 & $0.5-1.25$ & $\mathrm{Y}$ & NR & $0 \%$ & $0 \%$ & NR & NR & $23 \%$ & $10 \%$ & NR & $\mathrm{NR}$ \\
\hline Miyata [37] & 2007 & 15 & 30.1 & 1,312 & 0.2 & NR & $\downarrow$ & NR & NR & NR & NR & NR & NR & NR & NR \\
\hline Oommen [38] & 2001 & 28 & 26.6 & 796 & NR & NR & NR & NR & NR & NR & NR & NR & NR & NR & $43 \%$ \\
\hline Poets [39] & 1999 & 15 & 27.0 & 880 & $0.5-4$ & $\mathrm{Y}$ & $\downarrow$ & $0 \%$ & $0 \%$ & $0 \%$ & NR & NR & NR & NR & NR \\
\hline Roll [40] & 2004 & 15 & 26.0 & 740 & 0.5 & NR & NR & $0 \%$ & NR & NR & NR & NR & NR & NR & NR \\
\hline Sagi $[41]$ & 1983 & 5 & 27 & 876 & 2.5 & $\mathrm{~N}$ & $\downarrow$ & NR & NR & NR & NR & NR & NR & NR & NR \\
\hline Tay-Uyboco [42] & 1991 & $10 / 6$ & $30.0 / 26.2$ & $1,520 / 1,010$ & $1.5 / 1.4$ & $\mathrm{~N}$ & $\downarrow$ & $Y>1.6$ & $44 \%$ & $0 \%$ & NR & $50 \%$ & $6 \%$ & NR & NR \\
\hline \multicolumn{16}{|l|}{ Case report } \\
\hline De Villiers [43] & 1998 & 3 & $26-28$ & $812-1,020$ & $1.47-3.08$ & $\mathrm{~N}$ & NR & $0 \%$ & NR & NR & NR & NR & NR & NR & NR \\
\hline Dear [44] & 1984 & 2 & 26,28 & $880,1,200$ & 2.5 & NR & $\downarrow$ & NR & $100 \%$ & NR & NR & NR & NR & NR & NR \\
\hline
\end{tabular}

$\mathrm{NR}=$ Not reported; $\mathrm{ND}=$ no difference; $\mathrm{Y}=$ yes; $\mathrm{N}=$ no; $\uparrow=$ more during doxapram treatment; $\downarrow$ = less during doxapram treatment; $\mathrm{Y}>1.5=$ yes, doxapram dose $>1.5 \mathrm{mg} \cdot \mathrm{kg}^{-1} \cdot \mathrm{h}^{-1}$, $\mathrm{N} / \mathrm{n}=$ number of infants treated with doxapram/number of infants not treated with doxapram; $\mathrm{BW}=$ birth weight; dose $=$ doxapram dose $\left(\mathrm{mg} \cdot \mathrm{kg}^{-1} \cdot \mathrm{h}^{-1}\right)$; apnea $=$ apnea frequency; $\mathrm{HT}=$ hypertension; CNS = central nervous system irritability; IVH >2 = intraventricular hemorrhage grade 3 or 4; GI = gastrointestinal side effects; LFU = long-term follow-up; EEG act. = electroencephalography activity; R-PDQ = Revised Prescreening Developmental Questionnaire.

\section{Randomized Controlled Trials}

The 4 RCTs included a total of 137 infants with a GA $<32$ weeks and a birth weight $<1,500 \mathrm{~g}$. Doxapram was given in a dose between 0.5 and $2.5 \mathrm{mg} \cdot \mathrm{kg}^{-1} \cdot \mathrm{h}^{-1}$ and compared to either placebo $[13,14,16]$ or theophylline $[14-$ 16]. Barrington and Muttitt [13] included mechanically ventilated infants, while the other 3 RCTs included infants on noninvasive or no respiratory support [14-16]. The overall methodological quality of 3 RCTs was found to be fair to good $[13,14,16]$ (fig. 2). The study of Möller et al. [15] was qualified as weak because the methods of randomization or blinding were not clearly described (fig. 2). Furthermore, 1 infant was excluded from further analysis without reason [15]. Heterogeneity analysis could not be performed, because outcome measures could not be pooled in a forest plot.

\section{Short-Term Effects}

The 4 RCTs used different definitions for successful doxapram therapy: not failing extubation [13], cessation or reduction of apneic spells [14], an apnea rate below

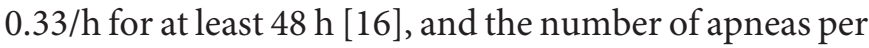
day [15]. Given the differences in outcome measurements, pooled analysis could not be performed. Barrington and Muttitt [13] showed no difference in extubation success between infants treated with doxapram ver- 
Fig. 2. Risk of bias of RCTs. White = Low risk of bias; gray $=$ unclear risk of bias; black $=$ high risk of bias. 'Other bias' defined as: 'concerns raised about multiple looks at the data with the results made known to the investigators, difference in patients enrolled in abstract and final publications of the paper' [11].

\begin{tabular}{|l|l|l|l|l|}
\hline \multicolumn{2}{|c|}{ Barrington [13] } & Eyal [14] & \multicolumn{1}{l|}{ Peliowski [16] Möller [15] } \\
\hline Adequate sequence generation & & & & \\
\hline Allocation concealment & & & & \\
\hline Detection bias & & & & \\
\hline Attrition bias & & & & \\
\hline Reporting bias & & & & \\
\hline Other bias & & & & \\
\hline
\end{tabular}

sus infants receiving placebo. Eyal et al. [14] showed no difference in treatment effect when comparing doxapram-treated infants versus aminophylline-treated infants. When doxapram was given to infants failing to respond to aminophylline treatment, $80 \%$ had a complete cessation of apneic spells. The study of Peliowski and Finer [16] showed a drop in apnea rate from $0.94 \pm 0.98$ to $0.42 \pm 0.55$ apneic spells/h in doxapram-treated infants. There was no difference in treatment effect when comparing doxapram-treated infants to theophylline-treated infants. The study by Möller et al. [15], using the continuous outcome apnea, showed a significantly lower number of apneas in the doxapram group compared to the theophylline group during 7 days of treatment [2.5 (range $0-34$ ) vs 7.0 (range $1-54$ ) apneas/week, $\mathrm{p}=0.037$ ]. The number of reported short-term adverse effects in the doxapram group was low and nonspecific in most cases [13-16].

\section{Long-Term Effects}

No long-term neurodevelopmental outcomes were reported in these RCTs.

\section{Cohort Studies}

Seven cohort studies were included [20-26], of which 2 were available in abstract form only [23, 24]. Five studies compared the outcomes of patients exposed to doxapram to those not exposed [20,21,23,24,26], 1 compared patients treated with high-dose doxapram (1.0-2.5 $\left.\mathrm{mg} \cdot \mathrm{kg}^{-1} \cdot \mathrm{h}^{-1}\right)$ to patients treated with low-dose doxapram $\left(0.2 \mathrm{mg} \cdot \mathrm{kg}^{-1} \cdot \mathrm{h}^{-1}\right)$ [25], and 1 study described a cohort of doxapram-treated infants [22]. The studies included a total of 935 infants of variable GA (table 1). Two studies assessed neurodevelopmental sequelae at 12-18 months' corrected age [23, 24]. Fischer et al. [21] and Czaba-Hnizdo et al. [20] had a low risk of bias, Yamazaki et al. [26], Kumita et al. [25] and Prins et al. [22] had a high risk of bias, the risk of bias could not be assessed for the publications in abstract form only (fig. 3).

\section{Short-Term Effects}

Six studies reported on different short-term outcomes [20-22, 24-26]. Yamazaki et al. [26] showed that almost $80 \%$ of the infants treated with doxapram had a partial or complete cessation of apnea. In addition, mortality was significantly reduced in the doxapram-treated group. Kumita et al. [25] reported that doxapram was effective by reducing $\mathrm{AOP}$ with a reduction in apnea frequency by more than $50 \%$ in 9 out of 11 infants in the high-dose group and in 18 out of 20 infants in the low-dose group. One infant in the high-dose group developed multiple gastric perforations. Prins et al. [22] reported that doxapram therapy was successful, defined as no need for endotracheal ventilation in $65 \%$ of the treated infants. Furthermore, successful treatment was associated with a longer duration of treatment and a lower mean dose. Ten 


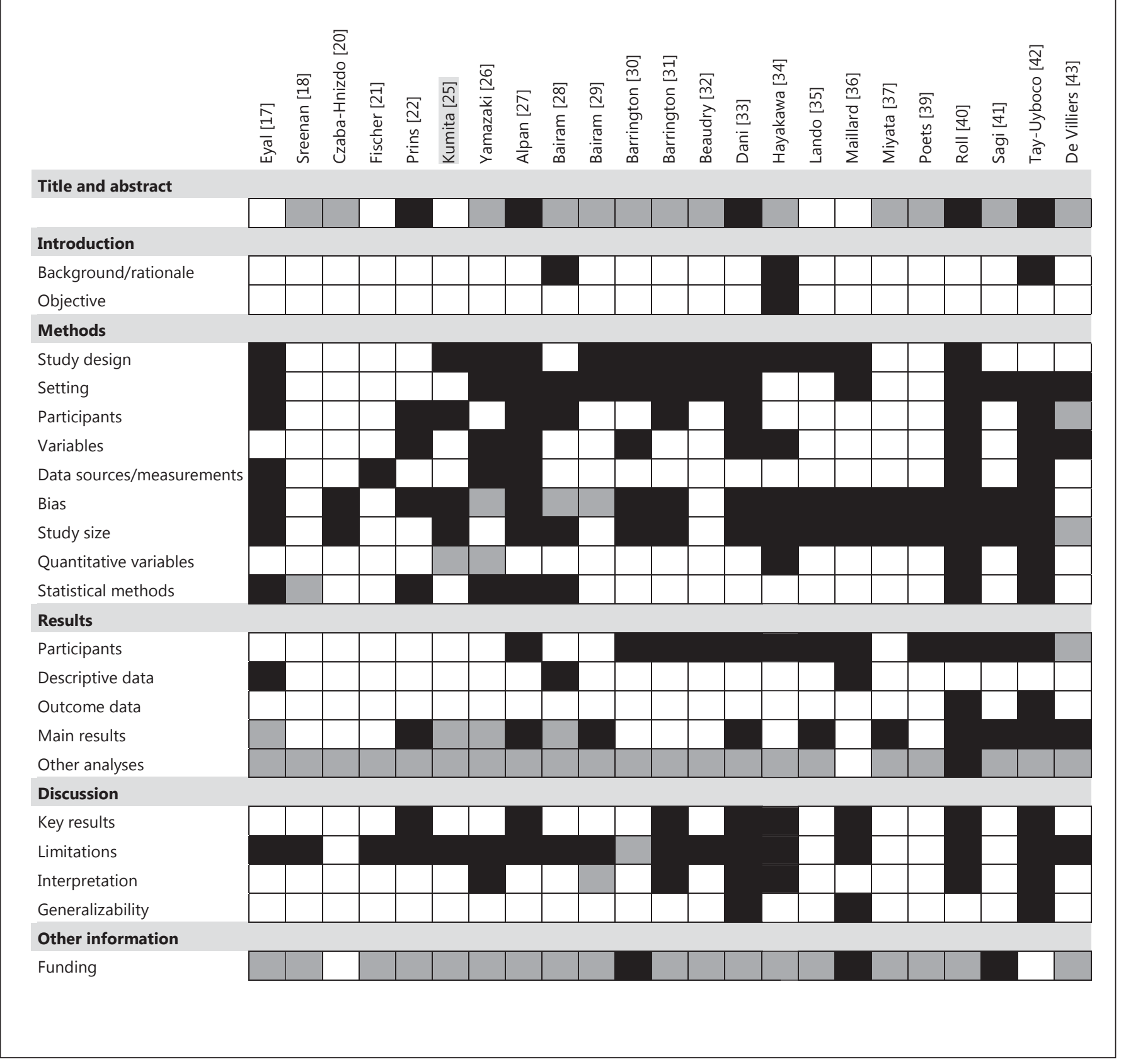

Fig. 3. STROBE statement, risk of bias. White = low risk of bias; gray = unclear risk of bias; black = high risk of bias.

Hove et al. [24] reported an increased risk of BPD, patent ductus arteriosus, and intraventricular hemorrhage >grade 2 in the doxapram-treated infants. The incidence of a single intestinal perforation, however, was significantly lower in the doxapram group. Other reported adverse effects were severe hypokalemia [21] and more fre- quent electrographic seizure activity on amplitude-integrated electroencephalography [20].

\section{Long-Term Effects}

Ten Hove et al. [24] found a significant reduction in the relative risk of having a mental developmental index 
$<1 \mathrm{SD}$ in infants treated with compared to without doxapram [relative risk $0.46(0.23,0.93), \mathrm{p}=0.03$ ]. Roignot et al. [23] did not find a difference in long-term neurodevelopmental outcomes.

\section{Case-Control Studies}

Two case-control studies including 718 preterm infants (GA <30 weeks) were identified $[18,19]$ (table 1). Both reported on long-term effects only. The methodological quality of the study by Sreenan et al. [18] was found to be good (fig. 2), whereas the risk of bias in the study of Zayek et al. [19] could not be assessed, because it was published in abstract form only.

\section{Long-Term Effects}

Sreenan et al. [18] found that infants with an isolated adverse mental development, defined as a mental developmental index $<70$ on the BSID-II, were treated with doxapram more often, for a longer duration (45.2 vs. 19.4 days) and with a higher cumulative dose (2.2 vs. $0.6 \mathrm{~g}$, respectively) compared to controls. Zayek et al. [19] showed that doxapram therapy did not increase the risk of neurodevelopmental impairment at 18 months' corrected age.

\section{Crossover Study}

The identified crossover study included 8 preterm infants recovering from respiratory distress syndrome, who were weaned from mechanical ventilation using doxapram or aminophylline [17]. The risk of bias of this study was judged to be high (fig. 3). The primary and only reported outcome, weaning from mechanical ventilation, was not statistically significantly different between doxapram and aminophylline.

\section{Case Series}

Sixteen case series were included, reporting a total of 324 preterm infants treated with doxapram (table 1) [2742]. One study was a pilot study described in a letter to the editor [29], and one study was only available in abstract form [38]. Both the characteristics of the included patients and the doxapram dosing regimen differed considerably between studies (table 1). In general, the case series had a moderate risk of bias (fig. 3).

\section{Short-Term Effects}

All studies reporting on apnea frequency showed a significant reduction after starting doxapram therapy [27$31,34,37,39,41,42]$. Four of the 9 studies reporting on blood pressure showed hypertension in patients treated with a doxapram dose exceeding $1.5 \mathrm{mg} \cdot \mathrm{kg}^{-1} \cdot \mathrm{h}^{-1}$ (table 1) [30-32, 42]. Five studies reported on possible gastrointestinal side effects such as NEC, abdominal distention, vomiting, or feeding intolerance $[32,34-36,42]$. The reported incidence of NEC ranged from 6 to $23 \%$ (table 1) $[29,32,33,39]$. Spontaneous intestinal perforation did not occur in any of the studies. Ten studies reported on possible short-term central nervous system effects of doxapram [27, 28, 30-34, 36, 39, 42]. Intraventricular hemorrhage $>$ grade 2 was observed in 1 study [32], and jitteriness, irritability, agitation, or frequent crying in 5 studies [27, 30, 32, 34, 42]. Only 1 study reported seizures in 2 infants during doxapram infusion [30], although both had other risk factors for neonatal seizures. Other less frequently reported adverse effects were premature tooth eruption [42] and a significant increase in QTc time [36]. Only 1 study reported on BPD and retinopathy of prematurity, showing no increased risk compared to the general reported incidences of these outcome measures [32].

\section{Long-Term Effects}

Four studies reported the effects of doxapram therapy on neurodevelopmental outcome [27, 32, 35, 38]. Beaudry et al. [32] reported retinopathy of prematurity stage 2 in 1 infant. Spastic diplegia was found at an age of 12 months in 1 of 11 treated infants [27], a reduction on the Revised Prescreening Developmental Questionnaire for every 10 days of treatment with doxapram in a group of 88 infants [35], and a mental developmental index $<70$ in $25 \%$ and a psychomotor development index $<70$ in $18 \%$ of the infants treated with doxapram [38].

\section{Case Report}

Two included studies were case reports, of which one was a full-text paper [43] and the other a letter to the editor [44]. The risk of bias of the full-text paper was assessed as high (fig. 3). It described 3 cases of very preterm infants with second-degree atrioventricular block caused by QT interval prolongation [43], while receiving doxapram dosages of $1.5,2.5$, and $3.0 \mathrm{mg} \cdot \mathrm{kg}^{-1} \cdot \mathrm{h}^{-1}$. The atrioventricular blocks disappeared when doxapram administration was discontinued. The other study reported a reduction in apnea rate in 2 preterm infants within hours of starting doxapram therapy at a dose of $2.5 \mathrm{mg} \cdot \mathrm{kg}^{-1}$. $\mathrm{h}^{-1}$ [44]. However, both infants became agitated with continuous erratic limb movements, excessive crying and disturbed sleep patterns. Their behavior returned to normal after discontinuing doxapram. 


\section{Discussion}

\section{Summary of Main Results}

This review summarizes all available evidence on the short- and long-term effects of doxapram for AOP. A total of 32 studies, including 4 RCTs and 28 observational studies were identified. These studies showed considerable differences in patient characteristics, study design, the doxapram dosing regimen, and reported outcome measures. A positive effect on apnea rate was found in all 16 studies reporting on this outcome [14-16, 25-32, 34, $39,41,42,44]$. Only a limited number of RCTs and casecontrol studies reported on short- and long-term adverse effects of doxapram use. Most of these did not show an increased risk of adverse effects. Case series have reported a wide range of possible adverse effects of doxapram use, although the interpretation of these results is difficult, because there is no control group and the data are potentially confounded by indication and publication. Reported possible adverse effects are hypertension at doses above $1.5 \mathrm{mg} \cdot \mathrm{kg}^{-1} \cdot \mathrm{h}^{-1}[30-32,42]$, gastrointestinal effects $[32,34,36,42]$, including NEC [32, 35, 36, 42], signs of CNS irritability [13, 27, 30, 32, 34, 42, 44], including seizures [20, 30], prolonged QT interval $[36,43]$ and hypokalemia [21].

\section{Quality of the Evidence}

Assessment of potential biases in methodology was not possible for 4 studies published as abstract. The methodological quality of the remaining 28 studies differed considerably (fig. 2, 3). Overall, the quality of most RCTs, case-control studies, and cohort studies was fair [13, 14, $16,18,19,21]$. There was a wide variety in quality of the included case series. In general, the case series had a moderate risk of bias, mainly because of an inadequate description of the methods and study limitations. The crossover study and both case reports had a high risk of bias $[17,43,44]$.

\section{Implications for Practice}

The overall applicability of this review is deemed low for several reasons.

First, there was a considerable heterogeneity between the included studies, for example differences in administered dose of doxapram, duration of therapy, definition of apnea and assessment of outcomes at different points in time. This heterogeneity may have compromised the validity and thus the results of the meta-analysis of the RCTs on doxapram use, as pooling of trial data assumes homogeneity of study design. Second, since only 4 RCTs with small sample size were identified, most of the studies in this review were case series and case-control studies.

Taking the limitations described above into account, the results suggest that doxapram might be useful in treating AOP. Whether this is also the case when doxapram is added to caffeine remains unclear. It is also unclear whether this possible short-term benefit on AOP will reduce the need for invasive mechanical ventilation and, more importantly, the incidence of BPD. It is important to acknowledge that doxapram might also have adverse effects, especially when using higher doses $(>1.5 \mathrm{mg}$. $\left.\mathrm{kg}^{-1} \cdot \mathrm{h}^{-1}\right)$. Given the limited high-quality evidence, it is unclear what the overall effects of benefits and harms are on long-term neurodevelopmental outcome following doxapram use. Based on these results, we cannot recommend the routine use of doxapram outside the realm of well-conducted randomized placebo-controlled trials for treating AOP. If used on an individual basis, clinicians should aim for the lowest possible effective dose of doxapram and monitor closely for possible adverse effects.

\section{Implication for Research}

A large, well-designed RCT on doxapram use for AOP is urgently needed. As caffeine is the standard of care for central AOP, doxapram should be studied as an adjuvant for infants failing caffeine treatment. This should be done in a blinded and placebo-controlled fashion. The study should include preterm infants with a high risk of adverse pulmonary and neurodevelopmental outcome and have sufficient power to assess both efficacy and safety. Data on the following primary outcome parameters should be collected: BPD at 36 weeks' postmenstrual age, mortality at 36 weeks' postmenstrual age and at discharge, and neurodevelopmental outcome using predefined definitions, diagnostic tests, and time points. Short-term benefits (i.e. time of extubation, duration of ventilation) and adverse effects (e.g. hypertension, gastrointestinal and CNS effects) can be reported as secondary outcomes. The use of open label doxapram outside the study protocol should be avoided as much as possible or based on an agreed protocol.

\section{Conclusion}

The present systematic review identified, appraised, and summarized all available evidence on doxapram use for AOP. No firm conclusions on the efficacy and safety of doxapram in preterm infants can be drawn based on the limited number of studies and level of evidence. For 
this reason routine use cannot be recommended. A large multicenter RCT is urgently needed to provide more conclusive evidence on whether to include or exclude this therapeutic option in the treatment of AOP.

\section{Disclosure Statement}

The authors have no potential conflicts of interest to declare.

\section{References}

1 Finer NN, Barrington KJ, Hayes BJ, Hugh A: Obstructive, mixed, and central apnea in the neonate: physiologic correlates. J Pediatr 1992;121:943-950.

2 Ruggins NR: Pathophysiology of apnoea in preterm infants. Arch Dis Child 1991;66:7073.

3 Martin RJ, Wang K, Koroglu O, Di Fiore J, Prabha KC: Intermittent hypoxic episodes in preterm infants: do they matter? Neonatology 2011;100:303-310.

4 Poets CF, Roberts RS, Schmidt B, Whyte RK, Asztalos EV, Bader D, Bairam A, Moddemann D, Peliowski A, Rabi Y, Solimano A, Nelson H: Association between intermittent hypoxemia or bradycardia and late death or disability in extremely preterm infants. JAMA 2015;314:595-603.

5 Davis PG, Schmidt B, Roberts RS, Doyle LW, Asztalos E, Haslam R, Sinha S, Tin W; Caffeine for Apnea of Prematurity Trial Group: Caffeine for Apnea of Prematurity Trial: benefits may vary in subgroups. J Pediatr 2010; 156:382-387.

6 Schmidt B, Anderson PJ, Doyle LW, Dewey D, Grunau RE, Asztalos EV, Davis PG, Tin W, Moddemann D, Solimano A, Ohlsson A, Barrington KJ, Roberts RS; Caffeine for Apnea of Prematurity Trial Investigators: Survival without disability to age 5 years after neonatal caffeine therapy for apnea of prematurity. JAMA 2012;307:275-282.

7 Schmidt B, Roberts RS, Davis P, Doyle LW, Barrington KJ, Ohlsson A, Solimano A, Tin W; Caffeine for Apnea of Prematurity Trial Group: Long-term effects of caffeine therapy for apnea of prematurity. N Engl J Med 2007; 357:1893-1902.

8 Henderson-Smart D, Steer P: Doxapram treatment for apnea in preterm infants. Cochrane Database Syst Rev 2004;4:CD000074.

9 Scott RM, Whitwam JG, Chakrabarti MK: Evidence of a role for the peripheral chemoreceptors in the ventilatory response to doxapram in man. Br J Anaesth 1977;49:227-231.

10 Benard M, Boutroy MJ, Glorieux I, Casper C: Determinants of doxapram utilization: a survey of practice in the French neonatal and intensive care units (in French). Arch Pédiatrie 2005; 12:151-155.

11 Higgins JPT, Green S: Cochrane Handbook for Systematic Reviews of Interventions Version 5.1.0 (updated March 2011). The Cochrane Collaboration, 2011. www.handbook. cochrane.org.
12 Vandenbroucke JP, von Elm E, Altman DG, Gotzsche PC, Mulrow CD, Pocock SJ, Poole C, Schlesselman JJ, Egger M: Strengthening the reporting of observational studies in epidemiology (STROBE): explanation and elaboration. Int J Surg 2014;12:1500-1524.

13 Barrington KJ, Muttitt SC: Randomized, controlled, blinded trial of doxapram for extubation of the very low birthweight infant. Acta Paediatr 1998;87:191-194.

14 Eyal F, Alpan G, Sagi E, Glick B, Peleg O, Dgani Y, Arad I: Aminophylline versus doxapram in idiopathic apnea of prematurity: a double-blind controlled study. Pediatrics 1985;75:709-713.

15 Möller JC, Austing A, Pust B, Kohl M, Reiss I, Iven $\mathrm{H}$, Gortner L: A comparative study about the therapeutic effect of theophylline and doxapram in apnoeic disorders (in German). Klin Pädiatr 1999;211:86-91.

16 Peliowski A, Finer NN: A blinded, randomized, placebo-controlled trial to compare theophylline and doxapram for the treatment of apnea of prematurity. J Pediatr 1990;116:648653.

17 Eyal FG, Sagi EF, Alpan G, Glick B, Arad I: Aminophylline versus doxapram in weaning premature infants from mechanical ventilation: preliminary report. Crit Care Med 1985; 13:124-125.

18 Sreenan C, Etches PC, Demianczuk N, Robertson CM: Isolated mental developmental delay in very low birth weight infants: association with prolonged doxapram therapy for apnea. J Pediatr 2001;139:832-837.

19 Zayek MM, Hamm CR, Trimm F, Whitehurst RM, Eyal F: Doxapram does not adversely affect neurodevelopmental outcome of extremely low birth weight infants at $12-18$ months of age. E-PAS 2008;4455:24

20 Czaba-Hnizdo C, Olischar M, Rona Z, Weninger M, Berger A, Klebermass-Schrehof $\mathrm{K}$ : Amplitude-integrated electroencephalography shows that doxapram influences the brain activity of preterm infants. Acta Paediatr 2014;103:922-927.

21 Fischer C, Ferdynus C, Gouyon JB, Semama DS: Doxapram and hypokalaemia in very preterm infants. Arch Dis Child 2013;98:F416F418.

22 Prins SA, Pans SJ, van Weissenbruch MM, Walther FJ, Simons SH: Doxapram use for apnoea of prematurity in neonatal intensive care. Int J Pediatr 2013;2013:251047.
23 Roignot O, Deforge H, Caspar C, Hascoet JM: Neurodevelopment and cognitive outcome of prematurely born children exposed to doxapram (DOX) in the neonatal period. E-PAS 2014; 1520:269.

24 Ten Hove CH, Onland W, Vliegenthart RJS, Wassenaer-Leemhuis AG, van Kaam AH: Long-term neurodevelopmental outcome after doxapram use for apnea of prematurity. E-PAS 2014;2917:248.

25 Kumita H, Mizuno S, Shinohara M, Ichikawa T, Yamazaki T: Low-dose doxapram therapy in premature infants and its CSF and serum concentrations. Acta Paediatr 1991;80:124127.

26 Yamazaki T, Kajiwara M, Itahashi K, Fujimura M: Low-dose doxapram therapy for idiopathic apnea of prematurity. Pediatr Int 2001; 43:124-127.

27 Alpan G, Eyal F, Sagi E, Springer C, Patz D, Goder K: Doxapram in the treatment of idiopathic apnea of prematurity unresponsive to aminophylline. J Pediatr 1984;104:634-637.

28 Bairam A, Faulon M, Monin P, Vert P: Doxapram for the initial treatment of idiopathic apnea of prematurity. Biol Neonate 1992;61: 209-213.

29 Bairam A, Vert P: Low-dose doxapram for apnoea of prematurity. Lancet 1986;1:793-794.

30 Barrington KJ, Finer NN, Peters KL, Barton J: Physiologic effects of doxapram in idiopathic apnea of prematurity. J Pediatr 1986;108:124129

31 Barrington KJ, Finer NN, Torok-Both G, Jamali F, Coutts RT: Dose-response relationship of doxapram in the therapy for refractory idiopathic apnea of prematurity. Pediatrics 1987;80:22-27

32 Beaudry MA, Bradley JM, Gramlich LM, LeGatt D: Pharmacokinetics of doxapram in idiopathic apnea of prematurity. Dev Pharmacol Ther 1988;11:65-72.

33 Dani C, Bertini G, Pezzati M, Pratesi S, Filippi L, Tronchin M, Rubaltelli FF: Brain hemodynamic effects of doxapram in preterm infants. Biol Neonate 2006;89:69-74.

34 Hayakawa F, Hakamada S, Kuno K, Nakashima T, Miyachi Y: Doxapram in the treatment of idiopathic apnea of prematurity: desirable dosage and serum concentrations. J Pediatr 1986;109:138-140.

35 Lando A, Klamer A, Jonsbo F, Weiss J, Greisen G: Doxapram and developmental delay at 12 months in children born extremely preterm. Acta Paediatr 2005;94:1680-1681. 
36 Maillard C, Boutroy MJ, Fresson J, Barbe F, Hascoet JM: QT interval lengthening in premature infants treated with doxapram. Clin Pharmacol Ther 2001;70:540-545.

37 Miyata M, Hata T, Kato N, Takeuchi M, Mizutani H, Kubota M, Yamazaki T: Dynamic QT/RR relationship of cardiac conduction in premature infants treated with low-dose doxapram hydrochloride. J Perinat Med 2007; 35:330-333.

38 Oommen P: Neurodevelopmental outcome of apneic infants treated with doxapram. EPAS 2001;2177. http://www.abstracts2view. com/pasall/view.php?nu=PAS1L_336.
39 Poets CF, Darraj S, Bohnhorst B: Effect of doxapram on episodes of apnoea, bradycardia and hypoxaemia in preterm infants. Biol Neonate 1999;76:207-213.

40 Roll C, Horsch S: Effect of doxapram on cerebral blood flow velocity in preterm infants. Neuropediatrics 2004;35:126-129.

41 Sagi E, Eyal F, Alpan G, Patz D, Arad I: Idiopathic apnoea of prematurity treated with doxapram and aminophylline. Arch Dis Child 1984;59:281-283.
42 Tay-Uyboco J, Kwiatkowski K, Cates DB, Seifert B, Hasan SU, Rigatto H: Clinical and physiological responses to prolonged nasogastric administration of doxapram for apnea of prematurity. Biol Neonate 1991;59:190200.

43 De Villiers GS, Walele A, Van der Merwe PL, Kalis NN: Second-degree atrioventricular heart block after doxapram administration. J Pediatr 1998;133:149-150.

44 Dear PR, Wheeler D: Doxapram and neonatal apnoea. Arch Dis Child 1984;59:903-904. 